\title{
Input features of Petroleum Hydrocarbon in Jiaozhou Bay
}

\author{
Dongfang Yang1, 2, 3, a, Peiyan Sun1, Lian Ju1, Qingyun Yu1 and \\ Jing Cao 1 \\ 1North China Sea Environmental Monitoring Center, SOA, Qingdao \\ 266033, China \\ 2College of Life Science, Shanghai Ocean University, Shanghai 201306, \\ China \\ 3College of Marine Science, Zhejiang Ocean University, Zhoushan \\ 31600, China \\ adfyang_dfyang@126.com
}

\begin{abstract}
Based on investigation dada on Petroleum Hydrocarbon (PHC) in April, August and November 1981 in Jiaozhou Bay, this paper analyzed the content, surces and input feature of PHC. Results showed that the content of PHC in study area ranged from 0.011-0.889 mg.L-1, and the highest value in April, August and November were $0.861 \mathrm{mg} . \mathrm{L}-1,0.889 \mathrm{mg} . \mathrm{L}-1$ and $0.176 \mathrm{mg} . \mathrm{L}-1$, respectively. PHC was mainly input to the bay by way of the major inflow rivers. Point source was dominating in dry season in Jiaozhou Bay, while both point and non-point sources were responsible in wet seasons. The pollution level of PHC was slight in dry season, while in wet season was severe. In April, the high risk areas of PHC content were occur in areas closed to the mouth of Haibo River. In August, the high risk areas of PHC content were expanded to areas closed to the mouths of Haibo River, Licun River and Dagu River.
\end{abstract}

Keywords: Petroleum Hydrocarbon; Input feature; Source; High risk area; Jiaozhou Bay

\section{Introduction}

PHC in marine environment are sourced from both natural and anthropogenic sources. In recent years, due to the rapid increase of petroleum producing and processing, ocean transportation, municipal runoff etc., PHC pollution in soil, river and ocean had been serious problem [1]. Understanding the pollution level, pollution source and input feature of PHC is essential to protect marine environment and to maintain the substainable development of marine economy.

Jiaozhou Bay is a semi-closed bay, located in economic developed regions of Shandong province, eastern China. Previous studies showed that this bay had been polluted by PHC [2-3]. Based on investigation dada on Petroleum Hydrocarbon (PHC) in April, August and November 1981 in Jiaozhou Bay, this 
paper analyzed the content, source and input feature of PHC, revealed the input features of $\mathrm{PHC}$, and provided basis for pollution control and environmental remediation.

\section{Material and method}

Jiaozhou Bay is located in the south of Shandong Province, eastern China $\left(35^{\circ} 55^{\prime}-36^{\circ} 18^{\prime} \mathrm{N}, 120^{\circ} 04^{\prime}-120^{\circ} 23^{\prime} \mathrm{E}\right)$. This bay is typically a semi-closed bay, the bay mouth is only $3 \mathrm{~km}$ width. The total area and average water depth are $390 \mathrm{~km} 2$ and $7 \mathrm{~m}$ respectively (Fig. 1). This bay has more than ten inflow rivers, including Haibo Rriver, Licun Rriver, Baisha Rriver, Dagu Rriver, Yanghe Rriver, and Loushan Rriver etc. All of which are seasonal rivers, and are input channels of various pollutants for PHC [2]. The data was provided by North China Sea Environmental Monitoring Center. The survey was conducted in April, August and November 1981. PHC in surface waters was monitored follow by The Chinese National Specification for Marine Monitoring [4].

\section{Results and discussion}

Content and source of PHC. The content of PHC in study area ranged from 0.011-0.889 mg. $\mathrm{L}^{-1}$, and the highest value in April, August and November were $0.861 \mathrm{mg} . \mathrm{L}^{-1}, 0.889 \mathrm{mg} . \mathrm{L}^{-1}$ and $0.176 \mathrm{mg} . \mathrm{L}^{-1}$, respectively. The pollution level of PHC in most of the monitroing sites in April and August ranged from Grade III to IV in Sea water quality standard (GB 3097-1997) of China, while in November mainly ranged from Grade I to II. It was clear that the pollution level of PHC was much more in wet season than in dry season. The anthropogenic sources of PHC could be further categoried into point and non-point sources. Most of the industrial and municipal wastewater was discharged to rivers from sewage pipes, these PHC containing wastewater was point source pollution. Meanwhile, exhaust gas from fossil fuel combustion was also PHC containing, and these PHC containing wastegas was non-point source pollution, which could be washed into river by rainfall-runoff. In case of point sources were dominating, the content of PHC would be relatively stable, while in case of non-point sources were dominating, the content of PHC would be relatively variable. The significant season variations of PHC content indicated that point source was dominating in dry season, while both point and non-point sources were responsible in wet seasons.

Input of PHC. In Jiaozhou Bay Region, PHC was mainly input to the bay by way of the major inflow rivers, which was similar to the input of $\mathrm{HCH}$ and $\mathrm{Hg}$ in this bay [5-8]. The PHC content in Jiaozhou Bay was determined by the input of $\mathrm{PHC}$ and the hydrodynamic condition of the bay. The high risk areas of PHC in this bay were showing spatiotemporal variabilities (Fig.1-3). In April, the precipitation in study area was beginning to increase, and the input of PHC form non-point sources was increasing. Haibo River was flowing throuth Qingdao, which was the biggest and most developed city in this region. Hence, the high risk areas of PHC content were firstly occur in areas closed to the mouth of 
Haibo River (0.861 mg. $\left.\mathrm{L}^{-1}\right)$. In August, along with the increasing of rainfall-runoff, the input of $\mathrm{PHC}$ from most of the rivers were increasing, the high risk areas of PHC content were expanded to areas closed to the mouths of Haibo River, Licun River and Dagu River (0.491-0.889 mg. $\mathrm{L}^{-1}$ ). In November, there was little input of PHC from non-point sources due to the lack of precipitation, and the pollution level of PHC was slight $\left(0.100-0.176 \mathrm{mg} . \mathrm{L}^{-1}\right)$.

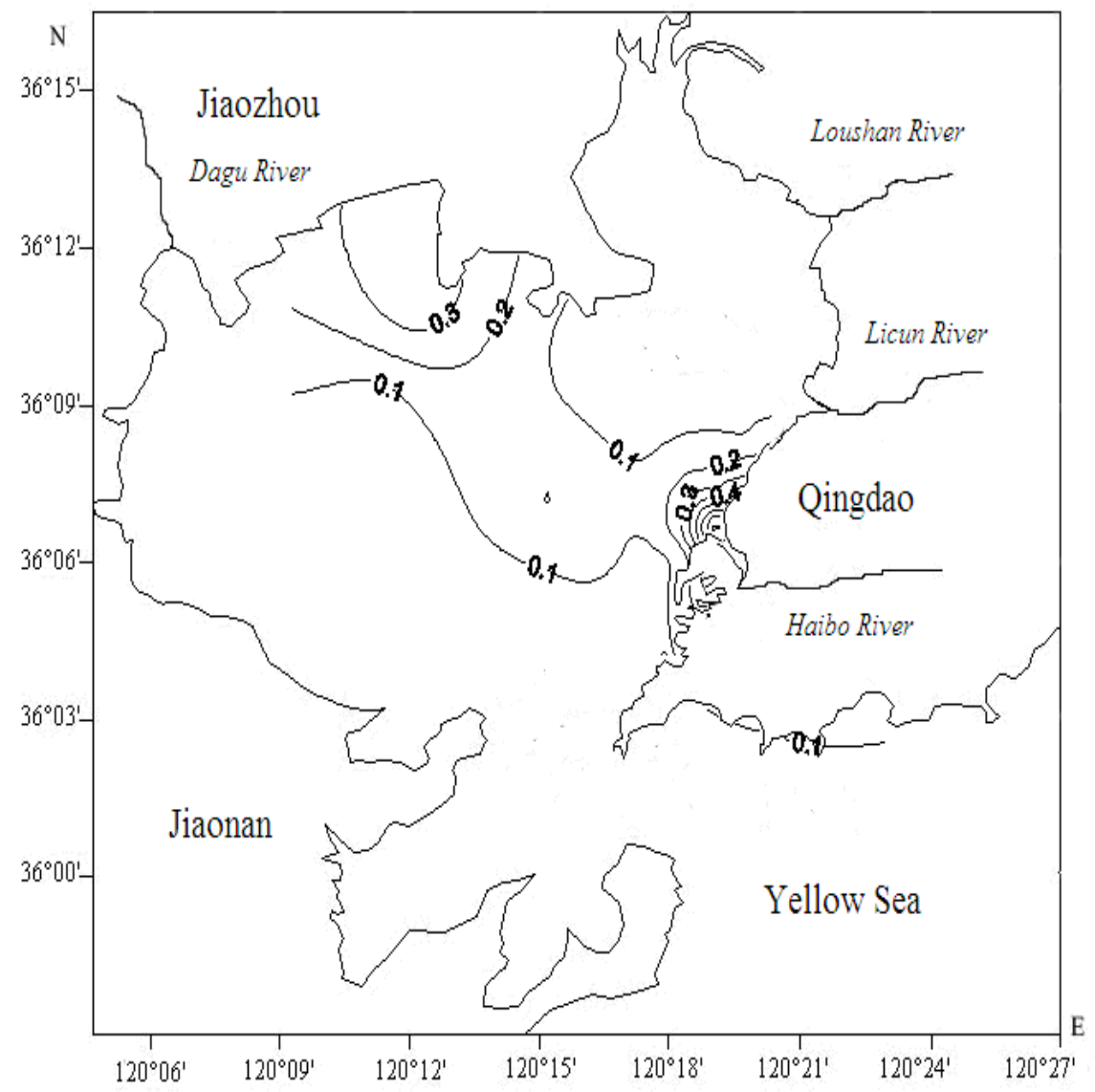

Fig.1 PHC distribution in the surface water in Jiaozhou Bay in April/mg. $\mathrm{L}^{-1}$ 


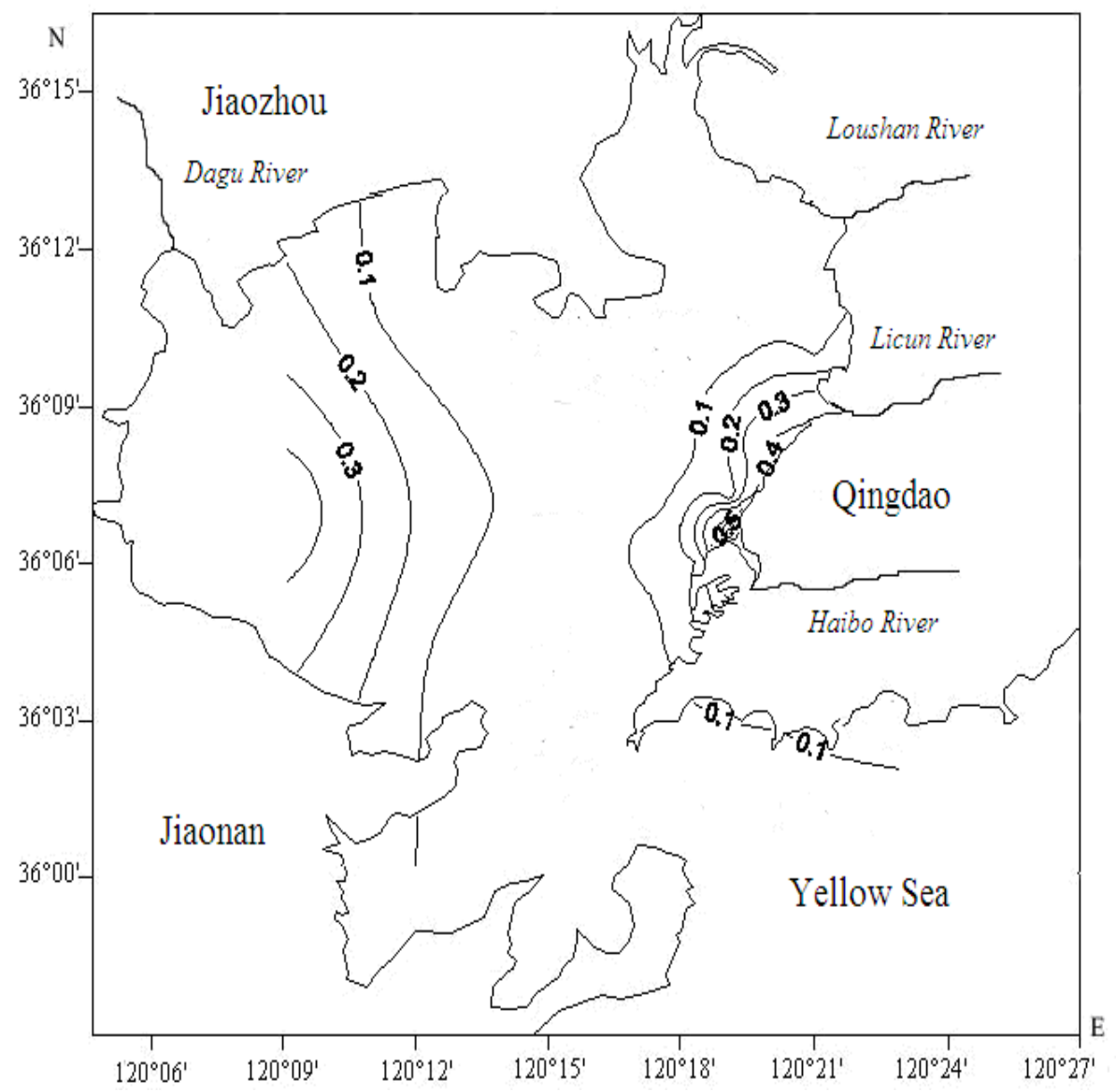

Fig.2 PHC distribution in the surface water in Jiaozhou Bay in August $/ \mathrm{mg} . \mathrm{L}^{-1}$ 


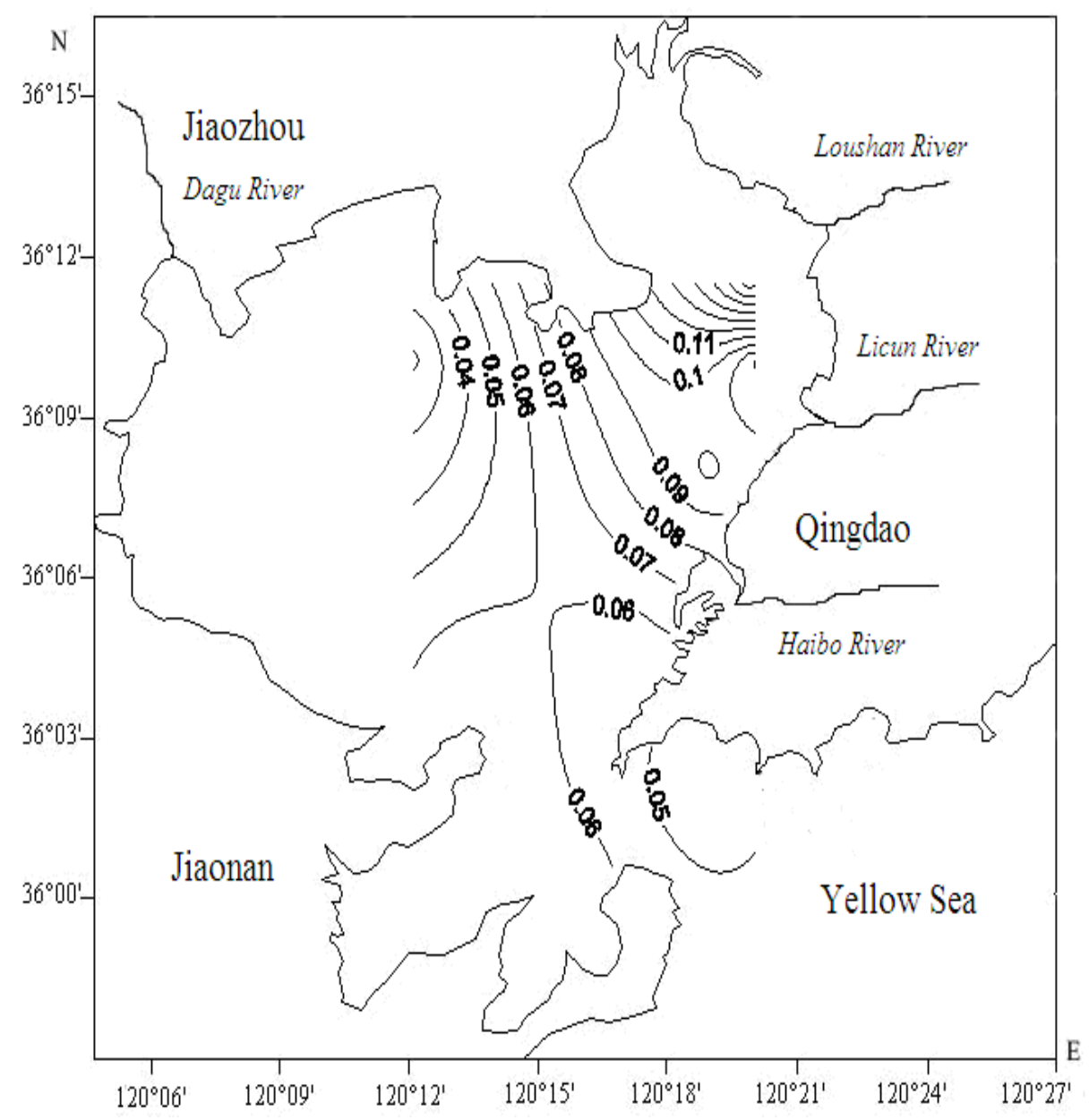

Fig.3 PHC distribution in the surface water in Jiaozhou Bay in November/mg. $\mathrm{L}^{-1}$

\section{Conclusion}

Point source was dominating in dry season in Jiaozhou Bay, while both point and non-point sources were responsible in wet seasons. PHC was mainly input to the bay by way of the major inflow rivers. The pollution level of PHC was slight in dry season, while in wet season was severe. In April, the high risk areas of PHC content were occur in areas closed to the mouth of Haibo River. In August, the high risk areas of PHC content were expanded to areas closed to the mouths of Haibo River, Licun River and Dagu River. These finding indicated that control of environment pollutions as their origins was the basis countermeasures, meanwhile, avoiding locations and times of high risk is necessary to aquaculture in this bay. 


\section{Acknowledgement}

This study was supported by Special Scientific Research Fund of Marine Public Welfare (201205012), Special Scientific Research Fund of Marine Public Welfare (201305012), and Scientific Research Found of Director of North China Sea Environmental Monitoring Center (05EMC16).

\section{References}

[1] Z.Q. Xiao: Oil-Gasfield Surface Engineering, Vol.6(1987), p.50-52. (in Chinese)

[2] D.F. Yang, Y.C. Zhang, Z. Jie, Q. Zhou and H.L. Yang: Open Journal of Marine Science, Vol.2(2011), p. 108-112.

[3] D.F. Yang, P.Y. Sun, C. Chen, H.Y. Bai and Q. Zhou: Coast. Engin., Vol.32(2013), p:60-72. (in Chinese)

[4] China's State Oceanic Administration. The specification for marine monitoring. (Ocean Press, Beijiang 1991). (in Chinese)

[5] D.F. Yang, Z.H. Gao, H.R. Cao, G.Y. Wen and L.L. Sun: Coast. Engin., Vol.27(2008), p:65-71. (in Chinese)

[6] D.F. Yang, Z.H. Gao, P.Y. Sun, L.L. Wang and L. Xie: Coast. Engin., Vol.28(2009), p:69-77. (in Chinese)

[7] D.F. Yang, H.R. Cao, Z.H. Gao, Q. Lu and Y.F. Qu: Mar. Environ. Sci., Vol.27(2008), p.37-39. (in Chinese)

[8] D.F. Yang, L.L. Wang, Z.H. Gao, L. Ju and J.P. Ju: Mar. Environ. Sci., Vol.28(2009), p.501-505. (in Chinese) 